\title{
Changes of the chlorogenic acid, caffeine, $\gamma$-aminobutyric acid (GABA) and antioxdant activities during germination of coffee bean (Coffea arabica)
}

\author{
Yeokyeong Kim¹, Yeongyil Kim², Deok-Young Jhon ${ }^{1,2 *}$ \\ ${ }^{1}$ Department of Food and Nutrition, Chonnam National University, 77, Yongbong-ro, Buk-gu, Gwangju, 61186, Republic of Korea, ${ }^{2}$ BioFood \\ Research Center, Chonnam National University, 77, Yongbong-ro, Buk-gu, Gwangju, 61186, Republic of Korea
}

\section{A B S TR A C T}

\begin{abstract}
This study was carried out to identify changes in functional materials during the germination of coffee seeds. Chlorogenic acid (CGA), caffeine, and $\gamma$-aminobutyric acid (GABA) was assayed by HPLC method while germinating coffee beans for 20 days. The contents of total phenolic compounds and total flavonoid compounds were measured by colorimetric method. Antioxidant activity was measured by both 2,2-diphenyl-2-pycryl hydrazyl (DPPH) radical scavenging activity assay and 2,2'-azino-bis-3-ethylbenzothiazoline-6-sulfonic acid $(A B T S \bullet+$ ) assay method. It was found that CGAs (5-caffeoylquinic acid (CQA), 4-CQA, 3-CQA), caffeine, and GABA increased and then decreased during germination. There were no significant changes in total phenolics, total flavonoids and antioxidant activities. Especially, all of the major isomers of CGA increased to the highest value at 10 days of germination, and GABA also increased significantly at the early stage of germination. This study showed that coffee beans changed into more functional food materials by germination and showed maximum functionality in appropriate germination conditions.
\end{abstract}

Keywords: Coffee Bean; Germination; Chlorogenic acid; Caffeine; $\gamma$-Aminobutyric acid

\section{INTRODUCTION}

Coffee is one of the most widely consumed beverages, and there are a variety of coffee drinks depending on the type of coffee beans, roasting and brewing methods. The chemical composition of coffee beans has been intensively and continuously studied since the beginning of the century, especially in terms of flavor compounds (Moon et al., 2009). Coffee has also received a lot of attention from many researchers involved in health-related research (Schilter et al., 2008). Many reports indicate that coffee bean contains many healthful antioxidants such as volatile heterocyclic compounds (Yanagimoto et al., 2002) and chlorogenic acids (CGAs) (Fujioka and Shibamoto, 2008). In recent years the intake of green coffee products has increased as a healthier option than roasted coffee (Kozuma et al., 2005; Sarriá et al., 2016).

CGA is a phenolic compound derived by the esterification of cinnamic acid, such as caffeic, ferulic and p-coumaric acids with (-)-quinic acid. CGAs mainly include caffeoylquinic acids (CQA), diCQA and feruloylquinic acid. According to many studies, coffee bean is one of the most important sources of polyphenols, especially CQA, in food and beverages (Wang and Ho, 2009). Green coffee bean is the major source of CGA in nature and its amount is 5-12 g/100 g dry matter (Farah and Donangelo, 2006; Farah et al., 2006). Recent studies have shown that CGA consumption is beneficial to health and is associated with decreased relative risk of cardiovascular disease, type 2 diabetes and Alzheimer's disease (Han et al., 2014), and antibacterial and anti-inflammatory activities (Almeida et al., 2006; dos Santos et al., 2006). Among the 8 CGA isomers present in green coffee beans, the concentration of 5-CQA is the highest (4-5 g/100g dry matter) (Moon et al., 2009).

Germination has been identified as an inexpensive and effective technique for improving grain quality (Wu et al., 2013). During germination some functional compounds

\footnotetext{
*Corresponding author:

Deok-Young Jhon, Department of Food and Nutrition, Chonnam National University, 77, Yongbong-ro, Buk-gu, Gwangju, 61186, Republic of Korea. Tel: +82-62-530-1335, E-mail: yjhon@gmail.com 
may become abundant, and some antinutrients may be destroyed (Kim et al., 2012). According to current research, germination increases $\gamma$-aminobutyric acid (GABA) in brown rice ( $\mathrm{Ng}$ et al., 2013). Recently, researchers have reported that while coffee beans germinate, CGA content increases and caffeine content decreases (Praphutphitthaya et al., 2016). The major CGA isomers that are contained in coffee beans are 5-CQA, 4-CQA, and 3-CQA. Although the three CGA isomers showed quite similar antioxidant activities, the order of DNA damage protective effect was 5-CQA > 4-CQA > 3-CQA.(Xu et al., 2012)

In this study, we investigated changes in the contents of major isomers of CGA during germination of coffee beans, and analyzed the changes of GABA and caffeine contents, and antioxidant activities.

\section{MATERIALS AND METHODS}

\section{Coffee}

Coffee seeds (Coffea arabica) with parchment harvested in Laos in 2015 were purchased from Club Green Coffee Co in Bolaven, Laos. The coffee seeds were kept at room temperature during this study. When germinating coffee seeds, the seed coat was removed by hand to prevent damage to the beans.

\section{Chemicals and reagents}

HPLC grade methanol and acetonitrile were purchased from J. T. Baker (Phillipsburg, NJ, USA). Triethyl amine and syringe filter $(0.45 \mu \mathrm{m})$, HPLC grade ethanol and water were purchased from Merck (Darmstadt, Germany). CGAs, caffeine, GABA, phenyl isothiocyanate, and Carrez reagents were purchased from Sigma-Aldrich (St. Louis, MO, USA).

\section{Germination of green coffee beans}

Green coffee beans were sterilized in 1\% sodium hypochlorite for $2 \mathrm{~min}$ (da Silva, 2002). The coffee seeds were then washed 3 times in sterile water and then immersed in sterile water at the same weight as coffee beans at $30^{\circ} \mathrm{C}$ for $14 \mathrm{~h}$ for imbibition. The soaked seeds were placed on gauze soaked in sterile water. To maintain the humidity, a water vat was placed in the incubator. During the germination of the coffee beans, the interior of the incubator was maintained at a relative humidity of $80 \%$ and a temperature of $30^{\circ} \mathrm{C}$. Sterilized water and air were supplied during the 20 -day germination process.

\section{Determination of caffeine, CGA and GABA}

The coffee and germinated coffee were dried at $60^{\circ} \mathrm{C}$ for $8 \mathrm{hr}$, powdered and passed through a sieve (200 mesh). $1 \mathrm{~g}$ of the powder was extracted with $10 \mathrm{ml}$ of boiled water $\left(95^{\circ} \mathrm{C}\right)$ for 1 minute by vortexing method. This was allowed to stand for 5 minutes, then centrifuged (10,000 X g, 2 min) and the supernatant was used for analysis.

Treatment of samples for caffeine and CGA analysis was performed in accordance with the technical bulletin of the Carrez clarification reagent kit (Moeenfard et al., 2014). Chromatoic separation was performed on an HPLC (LC-20AD, Shimadzu, Kyoto, Japan) equipped with a photodiode array detector. The analytical column was a LiChrospher $100 \mathrm{RP}-18$ column ( $5 \mu \mathrm{m}, 250 \mathrm{~mm}$ x $4.0 \mathrm{~mm})$ with a guard column. The mobile phase was sodium phosphate buffer solution $(1 \mathrm{~g} / \mathrm{L}$, adjusted to $\mathrm{pH} 7.2$ with phosphoric acid, solvent A) and acetonitrile (solvent B). The concentration gradient was programmed to change from solvent A to solvent B after $80 \mathrm{~min}$ (from 0 to $50 \mathrm{~min}$ $5 \%$ of B, 50 to $65 \mathrm{~min}$ increase to $80 \%$ of $\mathrm{A}, 65$ to $70 \mathrm{~min}$ $80 \%$ of $\mathrm{A}, 70$ to $80 \mathrm{~min}$ decrease to $5 \%$ of $\mathrm{A}$ ). The amount of the sample injected into the HPLC column was $5 \mu \mathrm{L}$, the flow rate of the mobile phase was $0.9 \mathrm{~mL} / \mathrm{min}$, and the temperature of the oven equipped with the column was set at $40^{\circ} \mathrm{C}$. Caffeine and CGAs were monitored and quantified at $272 \mathrm{~nm}$ and $325 \mathrm{~nm}$, respectively.

GABA was analyzed by an HPLC (LC-20AD, Shimadzu, Kyoto, Japan) method according to Rossetti and Lombard (1996). The diluted samples were filtered through a microsyringe filter, derivatized using ethanol/water/ triethylamine/phenylisothiocyanate $(7 / 1 / 1 / 1)$ to form PTC-GABA and injected into an HPLC. An ODS-C18 Shim-pack column $(5 \mu \mathrm{m}, 250 \mathrm{~mm} \times 4.6 \mathrm{~mm})$ was used as the analytical column. As the HPLC mobile phase, solvent A was a mixed aqueous solution ( $\mathrm{pH} 6.2$ ) of $1.4 \mathrm{mM}$ sodium acetate, $0.1 \%$ triethanolamine and $6 \%$ acetonitrile. Solvent B was $60 \%$ (v/v) acetonitrile. The solvent flowing into the column was set to change from solvent $A$ to solvent $\mathrm{B}$ with a linear concentration gradient for $60 \mathrm{~min}$. The flow rate of the mobile phase was $1.0 \mathrm{~mL} / \mathrm{min}$ and the column temperature was set at $46^{\circ} \mathrm{C}$. The amount of sample injected into the HPLC column was $5 \mu \mathrm{L}$. A PDA detector was used for detection of GABA and was monitored and quantified at $254 \mathrm{~nm}$.

\section{Extraction of phenolic compounds from coffee beans} The coffee beans were pulverized and then defatted with diethyl ether by Soxhlet extraction method $\left(8 \mathrm{hr}, 70^{\circ} \mathrm{C}\right)$ and dried overnight at room temperature. Then, $2 \mathrm{~g}$ of the flour was extracted with $240 \mathrm{~mL}$ of acetone/methanol/ water $(7 / 7 / 6)$ by shaking at $180 \mathrm{rpm}$ for $30 \mathrm{~min}$ (Cheong et al., 2013). The solution containing the extract was filtered through a Whatman PTFE membrane filter $(0.45 \mu \mathrm{m})$ and concentrated on a rotary evaporator (HS-2000N, Han Shin Science Co., Seoul, Korea) at $40^{\circ} \mathrm{C}$. The concentrated residue was redissolved in $50 \mathrm{~mL}$ of $80 \%$ aqueous methanol and stored at $-80^{\circ} \mathrm{C}$ and used for constituent analysis. 
Determination of total phenol and flavonoid and measurement of antioxidant activity

Total phenol and flavonoid contents in coffee bean extracts were quantitatively analyzed by the Folin-Ciocalteu method (Bravo et al., 2013) and the catechin hydrate method (Ozsoy et al., 2008), respectively. The degree of antioxidant activity was measured by both 2,2-diphenyl-2-pycryl hydrazyl (DPPH) radical assay (Sharma and Bhat, 2009) and ABTS•+ analysis (Sánchez-González et al., 2005). The total phenolic content was expressed as milligram of gallic acid equivalent (GAE) per gram of dry weight and the flavonoid content was expressed as milligram of catechin equivalent (CE) per gram of dry weight. The results of DPPH• and ABTS $\bullet+$ assay were expressed by $\mu$ mole L-ascorbic acid equivalents (Vit. CE) per gram of dry weight.

\section{Statistical analysis}

Statistical analysis of the data obtained from the experiments was performed with SPSS statistics version 23.0 (SPSS Inc., Chicago, IL, USA). All experimental data are expressed as mean \pm SD. Duncan's multiple range test was used to test differences in data mean values and was considered significant when $\mathrm{p}$-value $<0.05$.

\section{RESULTS AND DISCUSSION}

Coffee beverages have become widely used as favorite foods. However, it is difficult to find studies on the compositional changes during the germination process of coffee beans. The aim of this study was to identify changes in the content of major functional ingredients during germination of coffee seeds. Coffee beans have been germinated in order to improve the functions beneficial to human health. The morphological changes of coffee beans according to germination period are shown in Fig. 1. In this experimental condition, the length of the radicle at 10 day germination and 20 day germination were about 1 and $3 \mathrm{~mm}$, respectively. When judged only by appearance, these germinated coffee seeds corresponded to Stages $G$ and S-1, which correspond to 7th and 9th days of germination experiment results of da Rosa et al. (2010), respectively. The radicle of coffee seed germinated for 20 days was characterized by a light pink color.

The content of caffeine, CGA, total phenol or total flavonoid and the degree of antioxidant activity measured by DPPH $\bullet$ assay or ABTS $\bullet+$ method were measured at 5 - day intervals during germination of coffee beans. Fig. 2 shows the change in caffeine content. The content of caffeine was $1.18 \mathrm{~g} / 100 \mathrm{~g}$ db before germination. According to reported studies, the levels are 0.9 - $1.3 \mathrm{~g} / 100 \mathrm{~g} \mathrm{db}$ (Farah, 2012). It was found that coffee seeds germinated for 10 days contained the highest amount of caffeine.

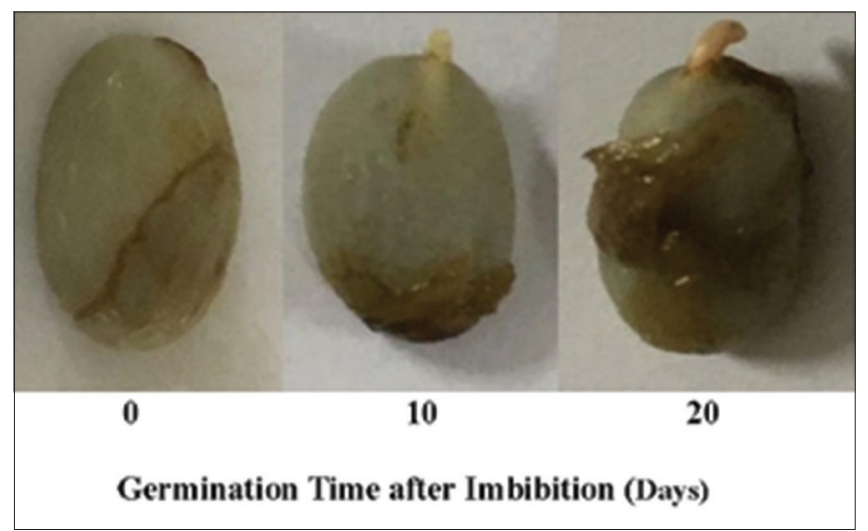

Fig 1. Germination of coffee bean. Parchment was removed and the germination was carried out with silver skin covered. Silver skin was swollen and peeled off by water during germination.

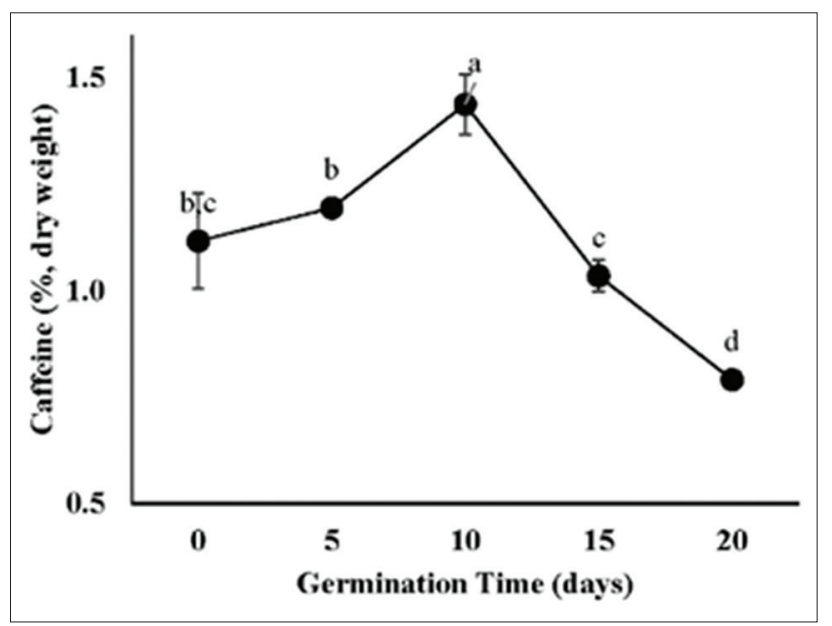

Fig 2. Caffeine content of germinated coffee bean The values designated by the different letters on the line are significantly different $(a=0.05)$.

The amount increased to $1.44 \mathrm{~g} / 100 \mathrm{~g} \mathrm{db}$, which is $122 \%$ of the amount of caffeine in the coffee beans before germination. After that, the amount decreased, and on the 20th day of germination, it decreased to about $67 \%$ of the non-germinated coffee bean. Praphutphitthaya et al. (2016) reported that during the germination of coffee seeds for 8 days, caffeine continued to decrease to $54 \%$. However, in this study, caffeine levels continued to increase for 10 days. Therefore, it is different from the results of the above researchers. On the other hand, Aneja and Gianfagna (2001) have reported that caffeine content in young growing cocoa leaves significantly increased by wounding or fungal infections. Therefore, it is thought that the caffeine pathway is inducible and the caffeine content can be increased or decreased depending on the difference of any conditions during germination of coffee beans.

The content of CGA in coffee beans also changed as the seed germination progressed. (Fig. 3) Similar to the results 


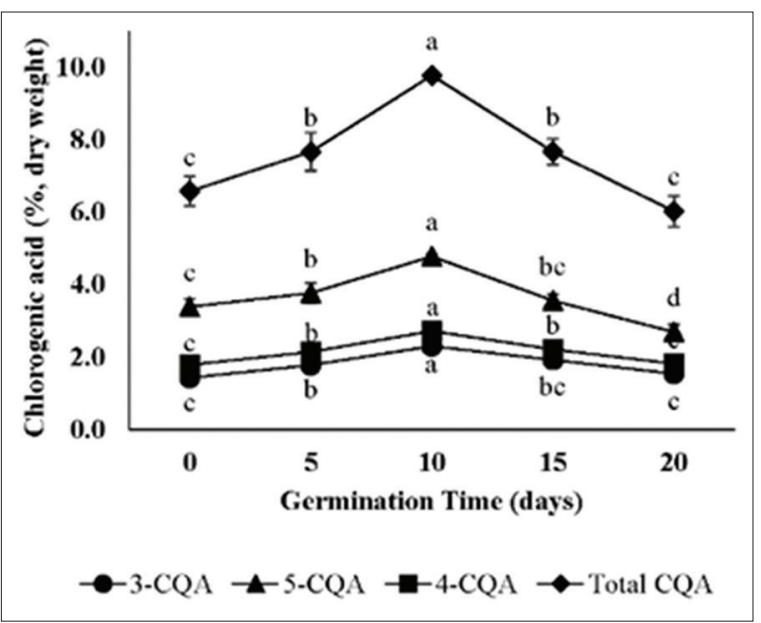

Fig 3. Chlorogenic acid (CGA) content of germinated coffee bean The values designated by the different letters on the same line are significantly different $(a=0.05)$.

of caffeine content, total CGA content was the highest at 10 days after germination, and its value was $9.78 \mathrm{~g} / 100 \mathrm{~g} \mathrm{db}$, which was about $70.7 \%$ higher than before germination. The isomers of CGA, i.e., 5-CQA, 4-CQA and 3-CQA, increased for 10 days after germination and decreased to the level of non-germinated coffee seeds at 20 days after germination. Among the isomers the contents of 5-CQA was much higher, followed by 4-CQA and 3-CQA, and the order did not change during the entire process of germination. By the way, Praphutphitthaya et al. (2016) reported that on the fourth day of germination the CGA content increased by $13.2 \%$ compared with that before germination, and the level was $5.1 \mathrm{~g} / 100 \mathrm{~g}$. CGA content decreased rapidly thereafter. Furthermore, the article did not mention the dynamics of the content of each isomer. Therefore, it was confirmed that during the germination of coffee seeds, the CGA content increased at the highest level. Many coffee drink consumers are paying attention to the content of CGA in coffee beverages. However, because CGA is destroyed by about $50 \%$ during roasting of coffee, high CGA-containing coffee beans may be required in roasting process (Moon et al., 2009). This study suggests that if the non-costly germination method is introduced into the production process of coffee beverages, it will have a positive effect on various aspects of the coffee industry because the content of CGA can be increased by germination.

GABA, a non-proteinaceous amino acid, is known to be an important inhibitory neurotransmitter (Boonstra et al., 2015; Erlander and Tobin, 1991). It is generally known that GABA increases during germination of plants (Park and $\mathrm{Oh}, 2007)$. In the case of brown rice, it has been reported that GABA increases by more than 10 times to $1 \mathrm{~g} / 100 \mathrm{~g}$ during germination. Therefore, the content of GABA was examined during germination of coffee seeds as shown in Fig. 4. The content of GABA in the coffee

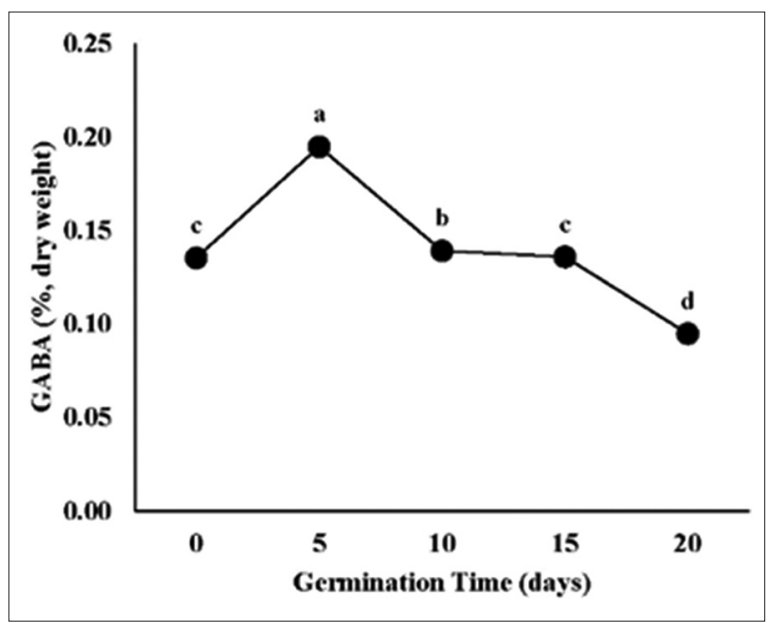

Fig 4. $\gamma$-Aminobutyric acid (GABA) content of germinated coffee bean The values designated by the different letters on line are significantly different $(a=0.05)$.

beans was $0.11 \mathrm{~g} / 100 \mathrm{~g}$. However, in the germination condition of this study, it became $0.19 \mathrm{~g} / 100 \mathrm{~g}$ at the 5 th day after germination initiation, which corresponds to $172 \%$ of the GABA content of non-germinated seeds. GABA decreased afterwards and became lower than the level before germination on the 20th day of germination. The content of GABA in coffee seeds is known to be affected by stresses such as drying and germination (Selmar et al., 2014).

Total phenolic content and total flavonoid content were $35.95 \mathrm{mg} \mathrm{GAE} / \mathrm{g} \mathrm{db}$ and $54.16 \mathrm{mg} \mathrm{CE} / \mathrm{g} \mathrm{db}$, respectively, in the coffee seed before germination. This amount did not change significantly during germination as shown in Table 1. The amount of CGA increased and then decreased significantly during the germination process. Nevertheless, the fact that the total phenol content did not change is a part that can be interpreted as the conversion between phenolic components. Table 2 shows that the antioxidative activities of DPPH• and ABTS • + were $166.6 \mu$ mole Vit. $\mathrm{CE} / \mathrm{g} \mathrm{db}$ and $223.79 \mu$ mole Vit. CE/g db. However, the amount repeatedly increased and decreased within the range of $5 \%$ during the germination process. There was no significant change in ABTS $\bullet+$ values. Therefore, during the germination process of coffee seeds, the antioxidant activity did not change as well as the total phenolic content and total flavonoid content.

\section{CONCLUSIONS}

Changes in the contents of major CGA isomers, GABA and caffeine and antioxidant activities were investigated during germination of coffee beans at $30^{\circ} \mathrm{C}$ for 20 days. The contents of all three CGA isomers increased until 10 days and then decreased. The maximum value of the 
Table 1: Total phenolic and flavonoid contents of germinated coffee bean

\begin{tabular}{lcc}
\hline $\begin{array}{l}\text { Germination } \\
\text { Time (days) }\end{array}$ & $\begin{array}{c}\text { Total phenol } \\
\text { contents } \\
\text { (mg GAE/g db) }\end{array}$ & $\begin{array}{c}\text { Flavonoid } \\
\text { contents } \\
\text { (mg CE/g db) }\end{array}$ \\
\hline 0 & $35.95 \pm 0.70^{\mathrm{ab}}$ & $54.16 \pm 0.00^{\mathrm{ab}}$ \\
5 & $35.14 \pm 1.04^{\mathrm{b}}$ & $51.92 \pm 2.55^{\mathrm{b}}$ \\
10 & $37.04 \pm 0.74^{\mathrm{a}}$ & $57.42 \pm 0.84^{\mathrm{a}}$ \\
15 & $34.59 \pm 0.11^{\mathrm{b}}$ & $52.47 \pm 2.52^{\mathrm{ab}}$ \\
20 & $35.14 \pm 0.54^{\mathrm{b}}$ & $49.91 \pm 2.51^{\mathrm{b}}$ \\
\hline
\end{tabular}

Data are means $\pm S D$, different lowercase letters in the same column indicate significant differences at $\mathrm{P}<0.05$

Table 2: Antioxidant activities of germinated coffee bean

\begin{tabular}{lcc}
$\begin{array}{l}\text { Germination } \\
\text { Time (days) }\end{array}$ & $\begin{array}{c}\text { DPPH } \\
(\mu \text { mole Vit. CE/g db) }\end{array}$ & $\begin{array}{c}\text { ABTS } \\
(\mu \text { mole Vit. CE/g db) }\end{array}$ \\
\hline 0 & $166.60 \pm 3.06^{\mathrm{c}}$ & $223.79 \pm 13.82^{\mathrm{a}}$ \\
5 & $170.91 \pm 0.93^{\mathrm{ab}}$ & $218.04 \pm 8.55^{\mathrm{a}}$ \\
10 & $174.92 \pm 0.90^{\mathrm{a}}$ & $222.75 \pm 14.30^{\mathrm{a}}$ \\
15 & $169.19 \pm 0.75^{\mathrm{bc}}$ & $212.14 \pm 10.83^{\mathrm{a}}$ \\
20 & $174.50 \pm 3.54^{\mathrm{a}}$ & $224.76 \pm 5.46^{\mathrm{a}}$ \\
\hline
\end{tabular}

Data are means \pm SD, different lowercase letters in the same column indicate significant differences at $\mathrm{P}<0.05$

sum of CGA isomers was 1.7-fold that of coffee beans before germination. GABA and caffeine contents were highest at 5 and 10 days of germination, respectively. And the amount increased 1.7-fold and 1.2-fold, respectively, before germination. However, the content of total phenol or flavonoids showing antioxidant activity slightly changed during germination. This study shows that while coffee beans germinate, there is a specific time range in which the content of each bioactive compound reaches its maximum.

\section{Author's contributions}

Ms. Yeokyeong Kim wrote the manscript and did all of the experiments, data analysis, and interpretation. This was part of her MSc work. Dr. Yeongyil Kim supplied raw coffee beans from Laos. Professor Deok-Young Jhon developed this project, supported all of the materials, and reviewed the paper. All the authors discussed together for this work.

\section{REFERENCES}

Almeida, A. A., A. Farah, D. A. Silva, E. A. Nunan and M. B. Gloria. 2006. Antibacterial activity of coffee extracts and selected coffee chemical compounds against enterobacteria. J. Agric. Food Chem. 54(23): 8738-8743.

Aneja, M. and T. Gianfagna. 2001. Induction and accumulation of caffeine in young, actively growing leaves of cocoa (Theobroma cacao L.) by wounding or infection with Crinipellis perniciosa. Physiol. Mol. Plant Pathol. 59(1): 13-16.

Boonstra, E., R. de Kleijn, L. S. Colzato, A. Alkemade, B. U. Forstmann and S. Nieuwenhuis. 2015. Neurotransmitters as food supplementshe effects of GABA on brain and behavior. Front. Psychol. 6: 1520.

Bravo, J., C. Monente, I. Juániz, M. P. De Peña and C. Cid. 2013. Influence of extraction process on antioxidant capacity of spent coffee. Food Res. Int. 50(2): 610-616.

Cheong, M. W., K. H. Tong, J. J. M. Ong, S. Q. Liu, P. Curran and B. Yu. 2013. Volatile composition and antioxidant capacity of Arabica coffee. Food Res. Int. 51(1): 388-396.

da Rosa, S. D. V. F., M. B. McDonald, A. D. Veiga, F. d. L. Vilela and I. A. Ferreira. 2010. Staging coffee seedling growth rationale for shortening the coffee seed germination test. Seed Sci. Technol. 38(2): 421-431.

da Silva, E. A. A. 2002. Coffee (Coffea arabica cv. Rubi) Seed Germination: Mechanism and Regulation. $\mathrm{PhD}$ thesis, Wageningen University.

dos Santos, M. D., M. C. Almeida, N. P. Lopes and G. E. de Souza. 2006. Evaluation of the anti-inflammatory, analgesic and antipyretic activities of the natural polyphenol chlorogenic acid. Biol. Pharm. Bull. 29(11): 2236-2240.

Erlander, M. G. and A. J. Tobin. 1991. The structural and functional heterogeneity of glutamic acid decarboxylase: A review. Neurochem. Res. 16(3): 215-226.

Farah, A. 2012. Coffee Constituents. Coffee: Emerging Health Effects and Disease Prevention, Wiley-Blackwell, Oxford, UK, p. 21-58.

Farah, A. and C. M. Donangelo. 2006. Phenolic compounds in coffee. Braz. J. Plant Physiol. 18: 23-36.

Farah, A., M. C. Monteiro, V. Calado, A. S. Franca and L. C. Trugo. 2006. Correlation between cup quality and chemical attributes of Brazilian coffee. Food Chem. 98(2): 373-380.

Fujioka, K. and T. Shibamoto. 2008. Chlorogenic acid and caffeine contents in various commercial brewed coffees. Food Chem. 106(1): 217-221.

Han, J., A. El Omri, K. Sasaki and H. Isoda. 2014. Caffeolyquinic Acid Protects Against Alzheimer's Disease Through Inhibition of Amyloid Beta-Induced Toxicity. Coffee in Health and Disease Prevention. $1^{\text {st }}$ ed, Elsevier, London, UK. P. 729-735.

Kim, H. Y., I. G. Hwang, T. M. Kim, K. S. Woo, D. S. Park, J. H. Kim, D. J. Kim, J. Lee, Y. R. Lee and H. S. Jeong. 2012. Chemical and functional components in different parts of rough rice (Oryza sativa L.) before and after germination. Food Chem. 134(1): 288-293.

Kozuma, K., S. Tsuchiya, J. Kohori, T. Hase and I. Tokimitsu. 2005. Antihypertensive effect of green coffee bean extract on mildly hypertensive subjects. Hypertens. Res. 28: 711.

Moeenfard, M., L. Rocha and A. Alves. 2014. Quantification of caffeoylquinic acids in coffee brews by HPLC-DAD. J. Anal. Methods Chem. 2014: 965353.

Moon, J.-K., H. S. Yoo and T. Shibamoto. 2009. Role of roasting conditions in the level of chlorogenic acid content in coffee beans: Correlation with coffee acidity. J. Agric. Food Chem. 57(12): 5365-5369

Ng, L. T., S. H. Huang, Y. T. Chen and C. H. Su. 2013. Changes of tocopherols, tocotrienols, gamma-oryzanol, and gammaaminobutyric acid levels in the germinated brown rice of pigmented and nonpigmented cultivars. J. Agric. Food Chem. 61(51): 12604-12611

Ozsoy, N., A. Can, R. Yanardag and N. Akev. 2008. Antioxidant activity of Smilax excelsa L. leaf extracts. Food Chem. 110(3): 571-583.

Park, K. B. and S. H. Oh. 2007. Production of yogurt with enhanced levels of gamma-aminobutyric acid and valuable nutrients using lactic acid bacteria and germinated soybean extract. Bioresour. Technol. 98(8): 1675-1679.

Praphutphitthaya, P., C. Tiyayon, T. Chetiyanukornkul and T. Pankasemsuk. 2016. Effect of brassin-like substance on the quality of early germinated arabica coffee bean (Coffea arabica L.). Pak. J. Biotechnol. 13(3): 165-172. 
Rossetti, V. and A. Lombard. 1996. Determination of glutamate decarboxylase by high-performance liquid chromatography. J. Chromatogr. B Biomed. Appl. 681(1): 63-67.

Sánchez-González, I., A. Jiménez-Escrig and F. Saura-Calixto. 2005. In vitro antioxidant activity of coffees brewed using different procedures (Italian, espresso and filter). Food Chem. 90(1-2): 133-139.

Sarriá, B., S. Martínez-López, R. Mateos and L. Bravo-Clemente. 2016. Long-term consumption of a green/roasted coffee blend positively affects glucose metabolism and insulin resistance in humans. Food Res. Int. 89(Part 2): 1023-1028.

Schilter, B., C. Cavin, A. Tritscher and A. Constable. 2008. Health Effects and Safety Considerations. Coffee, Blackwell Science Ltd, p. 165-183.

Selmar, D., M. Kleinwächter and G. Bytof. 2014. Metabolic Responses of Coffee Beans during Processing and Their Impact on Coffee
Flavor. Cocoa and Coffee Fermentations, CRC Press, Florida, p. $.431-476$.

Sharma, O. P. and T. K. Bhat. 2009. DPPH antioxidant assay revisited. Food Chem. 113(4): 1202-1205.

Wang, Y. and C. T. Ho. 2009. Polyphenolic chemistry of tea and coffee: A century of progress. J. Agric. Food Chem. 57(18): 8109-8114.

Wu, F., N. Yang, A. Toure, Z. Jin and X. Xu. 2013. Germinated brown rice and its role in human health. Crit. Rev. Food Sci. Nutr. 53(5): 451-463.

Xu, J. G., Q. P. Hu and Y. Liu. 2012. Antioxidant and DNA-protective activities of chlorogenic acid isomers. J. Agric. Food Chem. 60(46): 11625-11630.

Yanagimoto, K., K. G. Lee, H. Ochi and T. Shibamoto. 2002. Antioxidative activity of heterocyclic compounds found in coffee volatiles produced by Maillard reaction. J. Agric. Food Chem. 50(19): 5480-5484. 